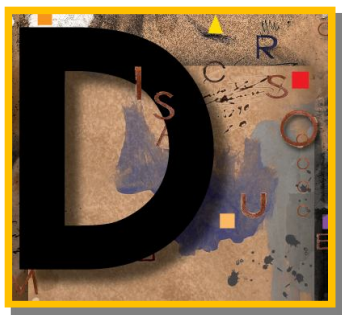

\title{
A CONSTRUÇÃO DE IDENTIDADES NEGRAS EM MEIO A PADRÕES BRANCOS DE BELEZA
}

\author{
F. Cordelia Oliveira da Silval ${ }^{l}(U n B)$
}

DISCURSOS CONTEMPORÂNEOS

EM

ESTUDO

ISSN 2237-7247

O presente artigo tem como objetivo refletir, à luz da Análise de Discurso Crítica (ADC), sobre a construção de identidades étnico-raciais no contexto brasileiro, tendo como base questões relacionadas à negação da beleza negra pela imposição, por meio dos discursos naturalizados e midiáticos (em propagandas de produtos para cabelos) de um padrão de beleza que nega o estereótipo negro e afirma modelos brancos. Com base em estudos de Bauman $(2009 ; 2005 ; 2001)$, Hall (2006), Wodak (1998), Woodward (2000), De La Torre (2002), Fanon (1980) - entre outros , verifica ainda a relação dessa negação com a ocorrência de crises de identidades para mostrar como, nesse cenário, as identidades construídas para negros são perpassadas por discriminações e preconceitos.

Palavras-chave: Identidades. Crises de identidades. Negros. Beleza.

This article aims to reflect, through the Critical Discourse Analysis (CDA), on the construction of ethnic and racial identities in Brazilian society, based on issues related to the denial of black beauty by the imposition, by means of naturalized speech and those of the media (in advertisements for hair products), a beauty standard that denies the stereotype black and reaffirm the white model. Based on studies of Bauman (2009; 2005; 2001), Hall (2006), Wodak (1998), Woodward (2000), De La Torre (2002), Fanon (1980) - among others - also notes the relationship between this negation and the crises of identity to show how, in this scenario, the identities constructed for blacks are laden with discriminations and prejudices.

Keywords: Identity. Identity Crisis. Blacks. Beauty.

\footnotetext{
${ }^{1}$ Doutora em Linguística pela Universidade de Brasília; membro do Cepadic e Pesquisadora do Instituto de Estudos e Pesquisas Educacionais Anísio Teixeira (INEP); pesquisadora associada do Programa de Pós-Graduação em Linguística da UnB (PPGL/UnB). E-mail: cordelia.prof@gmail.com.
} 


\section{Identidades étnico-raciais}

Para refletir sobre como as identidades étnico-raciais são construídas no Brasil, é importante considerar que esse conceito ganha relevância em um momento histórico e social de "desenraizamento das antigas matrizes de sentido", de fim dos grandes movimentos ideológicos (marxismo, socialismo), de fragmentação de valores e de dispersão das referências da vida cotidiana (LE BRETON, 2004, p. 15).

No atual momento sócio-histórico, Coracini (2003, p. 13) acredita que é importante estudar as identidades, uma vez que questionamentos e problematizações dos conceitos (aparentemente) estabelecidos acontecem em todas as áreas de conhecimento. Bauman (2009, p. 178), por sua vez, afirma que as identidades são, agora, o prisma por meio do qual outros aspectos-tópicos da vida contemporânea são localizados, agarrados e examinados. Pensando no interesse pelo estudo das identidades, De La Torre (2002, p. 29) atribui sua importância à necessidade humana de saber quem somos, como somos, de onde viemos, para onde vamos e a que grupos pertencemos. As identidades oferecem sentimento de pertença, são elemento regulador de nossos comportamentos "na medida em que motivações, sentimentos, valores, conceitos e atitudes devem se expressar em atuações congruentes" com nossas identidades.

A análise das identidades é, então, uma forma de expressar os múltiplos e complexos processos sociais, assim como uma tentativa de organizar os atores sociais que surgiram dos novos paradigmas políticos e econômicos; é também necessidade decorrente de nova relação indivíduo-coletivo-nação que explique essa interconexão e ofereça soluções possíveis para a existência social de todos os povos (CHÁVEZ, 2002, p. 44). Esses aspectos geram a exigência de refletir sobre o conceito de identidade e sobre sua realização na prática discursiva e social.

De La Torre (2002, p. 26) acredita ainda que o interesse pelo entendimento das identidades, bem como a importância que adquiriu na modernidade não são frutos de necessidade cognitiva (fazer e conhecer nosso lugar no mundo) ou prática (necessidades econômicas, sociais e políticas); ao contrário, representam uma necessidade existencial, comprovada pelos processos de repressão, de manipulação e de troca súbita ou de desestruturação intencional das identidades. Acredita, além disso, que o debate sobre as identidades relaciona-se ao estudo de seus processos de formação, à influência de instituições sociais sobre essa formação, à instauração e à manutenção de práticas sociais que contribuem para a crença e para a manutenção de sentimentos de pertença a um grupo social.

As identidades atuais, segundo Bauman (2001), pertencem à época “líquido-moderna" e são parte de um processo que comporta identificação e pertencimento. $\mathrm{O}$ autor alerta que esses processos não são, entretanto, sólidos como rochas, nem garantidos para toda a vida, uma vez 
que são negociáveis e reversíveis. Em uma série de escolhas, o sujeito precisa agir com determinação e manter-se firme para afirmar suas identidades e seu pertencimento. No entanto, em muitos casos, apesar da firmeza, o indivíduo sente-se deslocado em parte ou totalmente, o que é uma experiência desconfortável e perturbadora, porque as identidades "flutuam no ar, algumas de nossa própria escolha, mas outras infladas e lançadas pelas pessoas em nossa volta, e é preciso estar em alerta constante para defender as primeiras em relação às segundas" (BAUMAN, 2005, p. 19).

Além disso, Bauman (2005, p. 26) caracteriza as identidades como frágeis, provisórias, tarefas incompletas, estímulos, deveres e ímpetos à ação; elas são resultantes de ideias humanas, de fatos da vida. Assim, o conceito de identidade "nasceu da crise do pertencimento e do esforço que esta desencadeou no sentido de transpor a brecha entre o 'deve' e o 'é' e ergue a realidade ao nível dos padrões estabelecidos pela ideia - recria a realidade à semelhança da ideia”. Alerta ainda que uma suposta identidade coesa,

firmemente fixada e solidamente construída seria um fardo, uma repressão, uma limitação da liberdade de escolha. Seria um presságio da incapacidade de destravar a porta quando a nova oportunidade estiver batendo (BAUMAN, 2005, p. 60).

Ao contrário, a identidade é "inescapavelmente ambígua", é constituída de "luta simultânea contra a dissolução e a fragmentação; uma intenção de devorar e ao mesmo tempo uma recusa resoluta a ser devorado" (BAUMAN, 2005, p. 82-84).

O pertencimento, conceito atrelado ao de identidades, é alimentado constantemente pela prática da exclusão; ele integra os sujeitos ao mesmo tempo em que impõe e policia a fronteira entre "nós" e "eles". Enquanto isso, o "identificar-se com" é dar abrigo a um destino desconhecido, que não se pode influenciar, nem controlar (BAUMAN 2005, p. 28). Por isso, Bauman (2005) afirma que é mais prudente portar identidades, que são como um manto leve e pronto a ser despido a qualquer momento.

Bauman (2005, p. 44) assevera, além disso, que a identificação é fator poderoso na estratificação, uma de suas dimensões mais divisivas e fortemente diferenciadoras. Em um dos polos da hierarquia global, estão aqueles que constituem e desarticulam as suas identidades mais ou menos à própria vontade, escolhendo-as no leque de ofertas extraordinariamente amplo. No outro polo, abarrotam-se os que tiveram negado o acesso à escolha da identidade, que não podem manifestar suas preferências, que são oprimidos por identidades aplicadas e impostas identidades de que eles próprios se ressentem, mas não têm permissão de abandonar; identidades que estereotipam, humilham, desumanizam, estigmatizam. 
Ao tratar das identidades na pós-modernidade, Hall (2006) afirma que a identidade do sujeito pós-moderno é uma "celebração móvel”, formada e transformada em relação às maneiras pelas quais somos representados ou interpelados nos sistemas culturais que nos rodeiam. Falar da “celebração móvel” e das formas pelas quais somos representados é trazer à tona o jogo político na questão da identidade e considerar que toda identidade é arquitetada em prol de interesses socioeconômicos e políticos poderosos e que a mídia tem papel central nesse processo, uma vez que as identidades sociais construídas por ela assumem grande importância, condicionando e refletindo a forma como os membros da sociedade categorizam os sujeitos e como a sociedade, em si mesma, é reproduzida ou modificada.

Nesse primeiro momento, vimos que as identidades constituem conceito fundamental, mas estão envoltas em inconclusões, uma vez que pensá-las é trabalhar com multiplicidade de lugares sociais, sua interface e sua efemeridade. Nesse contexto, as classificações binárias perdem lugar em função da multiplicidade de experiências que perpassa a cultura contemporânea. Vejamos, então, aspectos do conceito de identidades para entender a construção identitária étnico-racial no contexto do Brasil do século XXI.

\section{Identidade: identificação e diferença}

Para muitos estudiosos, o conceito de identidades transita entre a identificação e a diferença, por isso, é relevante iniciar por esse ponto.

Silva (2000, p. 74) entende a identidade como conceito que se estabelece por meio de diferenças e de conceitos socioculturalmente construídos por atos de linguagem. Hall (2006, p. 330) acrescenta que "a diferença [...] é essencial ao significado, e o significado é crucial à cultura". Hall (2006, p. 85) afirma ainda que "cada identidade é radicalmente insuficiente em termos de seus "outros"” e que as identidades atuais são perpassadas pelos efeitos de fenômenos como o pós-colonialismo e a diáspora por que passam as culturas mundiais. Nesse sentido, acentua que a forma como a diferença é vivenciada nas sociedades colonizadas, como o Brasil, é

decisivamente distinta daquela que teria se essas culturas tivessem se desenvolvido isoladamente.

Pensando na diferença como formadora das identidades, De La Torre (2002, p.27) ressalta que ela não é apenas a suposição de que o indivíduo é ele e não outro, mas a consciência de ser ele mesmo. Então, o conceito de identidade alia-se com os de igualdade e de diferença; com a possibilidade de identificar-se ou não (não em relação binária, mas múltipla, pois o sujeito porta identidades e não apenas uma identidade). A identidade se constrói por meio de processo 
contrastivo, dialético ou dialógico, relacional e discursivo, em que nasce não das diferenças, mas da consciência sobre as diferenças (OLIVEIRA, 2006, p. 87).

Wodak (1998, p. 379) trata dos "discursos das diferenças", que são constituidores de práticas racistas por estabelecer práticas sociais, políticas e econômicas que privam grupos de recursos materiais e simbólicos, tornando-se uma forma de exclusão. A autora assevera que é necessário entender em que aspectos os "discursos das diferenças" distinguem-se do racismo. Aponta que o racismo é uma ideologia que consiste na

afirmação de uma desigualdade fundamentada nas diferenças naturais entre grupos (raças). Um conceito em que estão implícitas práticas de exclusão, discriminação, perseguição e aniquilamento e que é precedido, e acompanhado, por formas de ódio e de desdém (WODAK, 1998, p. 380).

O racismo, ainda segundo a autora, pode ser de três tipos:

- racismo ideológico: conjunto estruturado de representações de pontos de vista;

- racismo baseado em preconceitos: esfera de opiniões, de atitudes e de crenças;

- racismo de comportamento: utilização de práticas de discriminação, de perseguição e de aniquilamento.

Os alvos do racismo, por seu turno, podem ser estigmatizados por vários fatores, como:

- traços físicos reais ou atribuídos;

- traços espirituais ou culturais adquiridos social e historicamente;

- traços sociais;

- traços econômico ou sociais, como pertencer a grupo próspero ou não;

- traços políticos que integram ou excluem o grupo ao sistema de poder;

- traços religiosos.

- traços de nacionalidade, no sentido de integração a grupo étnico específico e de pertencer a determinado país (WODAK, 1998, p. 381).

Assim, os "discursos das diferenças" estabelecem distinção entre dois grupos - "nós" e os "outros" - com base em uma seleção de traços específicos atribuídos a um desses grupos.

\footnotetext{
${ }^{2}$ Ideia inicialmente desenvolvida por Stuart Hall (1989).
} 
De outro ponto de vista, Chávez (2002, p. 48) acredita que as identidades se constroem e se fortalecem com base no sentimento de pertença a determinado grupo e se realizam pela comparação e pela oposição a outro(s) grupo(s). Nesse processo de construção, entram em jogo as referências sociais positivas e negativas geradas pela identificação. Logo,

perguntar 'quem você é' só faz sentido se você acredita que possa ser outra coisa além de você mesmo; só se há uma escolha, e só se o que você escolhe depende de você; ou seja, só se você tem de fazer alguma coisa para que a escolha seja 'real' e se sustente" (BAUMAN, 2005, p. 25)'.

Diferenças coletivas ou grupais são, de acordo com Pierucci (1999, p. 105), componentes inevitáveis das sociedades humanas, resultantes de um processo de estratificação que é dúplice, uma vez que alia diferenciação e avaliação, "porquanto não há diferença, nos quadros culturais de qualquer sociedade, que não esteja sendo operada como valor, como diferença de valor ${ }^{4,}$. Além disso, ele ressalta que

diferenças coletivas, traços distintivos reais ou inventados, herdados ou adquiridos, genéticos ou ambientais, naturais ou construídos, partilhados vitalícia ou temporariamente por determinados indivíduos com outros determinados indivíduos, comuns a eles, mas não a todos os humanos, grupos de pertença ao longo de linhas demarcatórias de raça e cor, etnia e procedência [...] linhas que sempre falam de superioridade e inferioridade, de inclusão e de exclusão, algumas delas fortes, sublinhadas, outras tênues, quem dera invisíveis, atributos que quase sempre se acham fora do controle dos próprios indivíduos por eles identificados, mais ainda, cujo significado positivo ou negativo também escapa do controle individual apesar do eventual empenho em afastar a valoração negativa aderida ao traço coletivamente partilhado, marca sensível, o mais das vezes visível, de uma diferença significativa ${ }^{5}$ (PIERUCCI, 1999, p. 104-105).

Ademais, para Pierucci (1999, p. 106), a diferença convive com um dilema: mostrar-se ou esconder-se. E esse dilema pode levar a posições aparentemente antagônicas: tratar as pessoas diferentemente e enfatizar suas diferenças, o que pode estigmatizá-las (e excluí-las em matéria de emprego, de educação, de benefícios e de outras oportunidades) ou tratar de modo igual os diferentes, o que pode nos deixar insensíveis às suas diferenças, e isso, uma vez mais, termina por estigmatizá-las e barrá-las socialmente em um mundo que foi feito para certos grupos e não para outros. Assim, para o autor, "ser diferente é um risco de qualquer maneira".

\footnotetext{
${ }^{3}$ Aspas do autor.

${ }^{4}$ Grifos do autor.

${ }^{5}$ Grifo do autor.
} 
Ainda no âmbito de identidades étnico-raciais e de sua relação com identificação e com diferença, Pierucci (1999, p. 26) vê o racismo não como a rejeição da diferença, mas como a obsessão pela diferença, seja ela constatável, suposta, imaginada, atribuída. Assim, a rejeição da diferença vem da afirmação enfática da diferença. Para tanto, esclarece que

entre a afirmação da diferença (constatada ou inventada) e sua rejeição (que é onde o racismo se consuma), medeia uma série de procedimentos discursivos tendentes a aumentar a distância entre os signos, a exacerbar a diferença, a fazer funcionar a diferença, radicalizando-a no ato mesmo de enraizá-la no dado biológico (racismo clássico) ou no dado cultural dito 'irredutível' (neoracismo). Mas o importante é que o passo inicial é dado toda vez que a diferença é dita enfaticamente, toda vez que os discursos sobre a sociedade, os imaginários sociais, são "recentrados" enunciadas (PIERUCCI, p. 27-28).

De outro posicionamento, complementar ao de Pierucci, Hall (2006, p. 60) ressalta a "proliferação subalterna da diferença" na modernidade. Para explicar o processo, recorre ao conceito de différance, de Derrida. Explica que não há divisões binárias de diferença entre o que é absolutamente o mesmo e o que é o outro, mas uma "onda de similaridades e diferenças, que recusa a divisão em oposições binárias fixas”. Nesse sentido, os indivíduos e suas identidades estão cada vez mais "hibridizados" (HALL, 2006, p. 76). Em nossa cultura, por exemplo, o negro pode assumir o cabelo crespo como forma de valorizar a estética e a beleza negra, mas, para ser aceito no mercado de trabalho, vê-se, muitas vezes, obrigado a se adaptar ao padrão de cabelo socialmente valorizado: liso.

É relevante mencionar que, no mundo contemporâneo, essas fronteiras entre identidades são fluidas, em função de crises de identidades que caracterizam a pós-modernidade e de rápidas mudanças sociais que afetam papéis e identidades sociais. Nesse sentido, De La Torre (2002, p. 28) aponta que "os limites não são sempre essenciais, estáveis ou totalmente objetivos, mas quase sempre relativos, cambiantes, emergentes e socialmente construídos”. Além disso, eles podem ser mais ou menos objetivos e reais, ou mais ou menos subjetivos, reforçados ou manipulados por relações de poder ou pela mídia.

Portanto, ao pensar identidades e ao analisá-las, é preciso considerar que o conceito transita entre esses dois polos: identificação (igualdade, semelhança, pertença) e diferença (diferenciação, oposição), que não constituem as únicas possibilidades. Eles fazem parte de um

\footnotetext{
${ }^{6}$ Aspas do autor.
} 
rol de posições pelas quais os sujeitos transitam. Esse movimento é socialmente construído por práticas e por discursos.

\section{Crise de identidades étnico-raciais}

As identidades são fragmentadas e apresentam contradições com as quais o sujeito precisa lidar para negociar os diferentes papéis que exerce. Essas contradições desencadeiam crises de identidade. A crise de identidade é, consoante Dubar uma

perturbação de relações relativamente estáveis entre elementos estruturantes da actividade (produção e consumo, investimentos e resultados, etc.). A actividade [...] é a identificação, isto é, o facto de categorizar os outros e a si próprio (DUBAR, 2006, p. 14).

Ao abordar a construção e a crise das identidades pessoais, Dubar (2006, p. 142) menciona que, nas sociedades pós-modernas, a depressão é o exemplo mais comum dessa crise, advinda da mudança de modelo cultural com o qual homens e mulheres são confrontados. Acrescenta que "o imperativo de ser si próprio, de se realizar, de construir sua identidade pessoal, de se ultrapassar, de ter bom desempenho, engendra esta doença identitária às vezes crônica". Hoje, para ele, o indivíduo é "trajetória à conquista de sua identidade pessoal". Dubar acredita que as crises de identidade perturbam a imagem que o sujeito faz de si, sua autoestima, a definição que a pessoa dava de "si a si própria". Assim, a antiga configuração identitária torna-se “insustentável, impossível, corporalmente insuportável” (DUBAR, 2006, p. 144) e pode levar o sujeito a fechar-se em si mesmo. Uma das consequências possíveis dessa crise é a busca de culpados; nesse processo, podem aparecer os bodes expiatórios.

No contexto social brasileiro, um aspecto da crise de identidade étnico-racial diz respeito à aceitação étnico-racial e à negação da identidade inferiorizada construída para o negro. Como afirma Bauman (2001, p. 48), "viver diariamente com o risco da auto-reprovação e do auto-desprezo não é fácil”.

As crises de identidade são motivadoras de um fenômeno estudado por Fanon (1980, p. 105): o casamento entre brancos e negros como forma de o negro livrar-se (e aos seus descendentes) dos estigmas vividos em decorrência de sua origem étnico-racial. Ele acredita que, no que se refere ao casamento interracial, é possível perguntar em que medida ele não é "algumas vezes para o cônjuge de cor uma espécie de confirmação subjetiva do extermínio em si mesmo e aos seus próprios olhos do preconceito de cor de que durante muito tempo sofreu". Em muitos casos, Fanon (1980, p. 105) afirma que o homem e a mulher negra aceitam casar-se com 
cônjuge considerado socialmente inferior (mas branco) devido à possibilidade de "desracialização" que o matrimônio oferece, assim "o facto de desposar uma pessoa de raça branca parece ter preponderado sobre qualquer outra consideração. Aí encontram o acesso à igualdade total".

Há, nesse movimento, uma faceta da crise de identidade étnico-racial, marcada pela dificuldade de aceitação e de superação das características e do dos papéis sociais atribuídos ao negro. Essas crises são resultantes também de cultura da globalização que propõe a homogeneidade e a padronização. Devido a isso, as diferenças tornam-se meios de exclusão social e de autonegação, uma vez que todos querem pertencer à aldeia global.

Nesse contexto de crise, a luta pelo reconhecimento de nossas identidades ocorre em dois níveis: um externo e um interno. No interno, elaboramos nosso encontro com o outro. No externo, na esfera pública, trabalhamos a aceitação das diferenças. Isso ocorre porque as identidades

são construídas no interior das relações de poder. Toda identidade é fundada

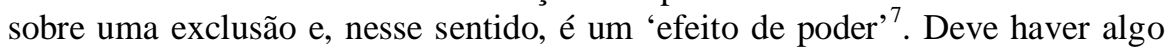
'exterior' a uma identidade. Esse 'exterior' é constituído por todos os outros termos do sistema cuja 'ausência' ou falta é constitutiva de sua presença (HALL, 2006, p. 80).

Identidades individuais e sociais são conceitos culturalmente definidos. Essas representações incluem as práticas de significação e os sistemas simbólicos, que produzem sentidos e posicionam os sujeitos. Na modernidade, as identidades são perpassadas por fatores comuns, motivados pela globalização, causando o aparecimento de identidades "sem pátria", formadas por uma única realidade cultural, o que corresponde ao fenômeno de diáspora (WOODWARD, 2000, p.17).

Hall (2006, p. 26), ao abordar a diáspora, afirma que "as nações não são apenas entidades políticas soberanas, mas "comunidades imaginárias"”. Enfatiza que "na situação de diáspora, as identidades tornam-se múltiplas e que, contrariamente ao que se possa pensar, em muitos casos, são fortalecidas". É o que ocorre com comunidades que, mesmo distantes de sua origem, mantêm traços de sua identidade local.

O conceito de diáspora relaciona-se ao de identidade cultural, que carrega traços de unidade essencial, de unicidade primordial, de indivisibilidade e de mesmice. Além disso, "presume-se que a identidade cultural seja fixada no nascimento, seja parte da natureza, impressa

\footnotetext{
${ }^{7}$ Aspas do autor.
} 
através do parentesco e da linguagem dos genes, seja constitutiva de nosso eu interior" (HALL, 2006, p. 27).

Analisando o panorama nacional, Martins (2007, p. 97) afirma que a consciência negra no Brasil se propôs e se afirma pelo modo branco de ver o negro. Para ele, "no fundo, a história branca desta sociedade negra não deixou ao negro senão a alternativa de ser branco". Esse fato é o desencadeador da crise identitária étnico-racial vivida pelo negro no Brasil: ser negro em um contexto que exige a brancura. Todas as demais crises são decorrentes dessa imposição da branquidade a um povo que não a possui.

\section{Identidades em crise: negação do estereótipo e da beleza}

Para ilustrar a crise identitária vivenciada pelo negro brasileiro, alguns aspectos de nossa realidade podem ser analisados para mostrar a exigência de branquidade ou o apagamento do sujeito negro de nosso discurso e de nossas práticas. Serão aqui apresentados aspectos relativos à negação do estereótipo físico e da beleza do negro. A construção de identidades acontece, desenvolve-se e se fortalece em múltiplos âmbitos, um deles é o estético, por isso é relevante pensar a beleza negra.

Gomes $(2006)^{8}$ pesquisou a constituição de identidades negras com base em dois aspectos: cabelo crespo e corpo, como aspectos culturais que, aliados a outros, resultam em um dos conflitos que perpassam a formação da identidade do negro no Brasil. Para a autora, esses fatores são essenciais em um processo de formação identitária que se dá pelo contraste, pela negociação, pela troca, pelo conflito e pelo diálogo com o outro. Esses elementos participam do processo de "tornar-se negro". Segundo Gomes (2006, p. 21), para 'entender o 'tornar-se negro' em um contexto de discriminação, é preciso considerar como essa identidade se constrói no plano simbólico", no qual são considerados valores, crenças, rituais, mitos e linguagem. Gomes (2006) ressalta a ideia de que as identidades não se constroem em isolamento, é necessária a participação do outro para intermediar a construção, para negociá-la e, principalmente, para reconhecê-la.

Pensando a relação entre belo e feio, Novaes $(2006$, p. 28) vai além e aponta que a importância do binômio "beleza-feiúra" ultrapassa o aspecto físico e adentra a avaliação moral, chegando à atribuição de características morais positivas aos considerados mais belos, pois "eles são vistos como mais amáveis, sensíveis, flexíveis, mais confiantes neles mesmos”. Força,

\footnotetext{
${ }^{8}$ A pesquisa foi realizada em quatro salões de Belo Horizonte, Minas Gerais; dois estão localizados no centro da cidade e dois em regiões periféricas.
} 
equilíbrio, sociabilidade, prestígio profissional, vida bem-sucedida e casamento feliz são predicados associados aos avaliados como belos e negados aos considerados feios.

No Brasil, há conflito com relação ao conceito de beleza, pois há um padrão ideal (branco) e um padrão real (negro, pardo, mestiço). Nesse contexto conflituoso, vários aspectos entram em cena: corpo, pele, altura, cabelos... Isso em uma sociedade que, cada vez mais, valoriza a estética e a beleza. Logo, não pertencer ao padrão pode gerar dois tipos de comportamento: a autoaceitação (consciência com relação ao próprio corpo) ou a autonegação (encobrimento dos aspectos que caracterizam o sujeito como não pertencente ao grupo considerado padrão).

No caso do negro, um dos grandes problemas é o cabelo. Para Gomes (2006, p. 27), ele pode ser entendido como forma de camuflar o pertencimento étnico-racial ou como modo de representar o reconhecimento das raízes africanas, servindo como reação, resistência e denúncia contra o racismo. Pensado nesse sentido, Gomes (2006, p. 22) afirma que "para o negro, a intervenção no cabelo e no corpo é mais que uma questão de vaidade ou de tratamento estético. É identitária". Esse aspecto é relevante porque usamos cabelo e cor da pele como critérios para classificar as pessoas nas várias etnias existentes no País.

Gomes (2006, p. 34) reflete ainda sobre as estratégias individuais desenvolvidas por negros e negras para construirem suas identidades. Afirma que "o fato de estar integrado ou de se reconhecer pertencente a um grupo étnico-racial não elimina os conflitos diários e os dramas pessoais vividos pelos negros na esfera da subjetividade". Logo,

a rejeição do corpo negro pelo negro condiciona até mesmo a esfera da afetividade. Toca em questões existenciais profundas: a escolha da parceira, a aparência dos filhos que se deseja ter. Nesse caso, estamos diante de uma rejeição que se projeta no futuro, nos descendentes que poderão vir. A melhor forma de se precaver contra essa possibilidade é 'clarear a raça' desde já, na escolha da parceira branca. O tipo de cabelo é o que orienta a escolha. Nesse caso, o cabelo simboliza a possibilidade do embranquecimento ou seu impedimento (GOMES, 2006, p. 140).

Esse processo conflitivo é construído socialmente, vivido e aprendido no grupo e na família. Assim, a rejeição ou a aceitação do ser negro é construída social e historicamente e permeia a vida do sujeito em todos os ciclos: infância, adolescência, vida adulta e velhice.

Quando a sociedade brasileira olha para o negro e para a negra e os destitui do lugar da beleza, ela afirma uma determinada proposição, um julgamento em relação ao negro e sua pertinência étnico/racial, o que pode ou não ser internalizado pelo sujeito. Contraditoriamente, ao tentar destituí-los do lugar da beleza, essa mesma sociedade reconhece-os como negros, uma vez que, para se rejeitar, é preciso antes reconhecer (GOMES, 2006, p.146). 
O negro vive, ainda de acordo com Gomes (2006, p. 147), um processo de "negação/aceitação" de sua condição de negro. Para a autora, "o sentimento de negação é um componente do processo identitário do negro brasileiro ao longo da história”. No entanto, há também negação do ser negro, que, para ela, é um processo mais danoso e mais complexo, pois envolve "negar-se a si mesmo e ser totalmente ignorado". Essa negação produz-se em um contexto de violência que perpassa a vida do negro "a ponto de se constituir em representações negativas do negro sobre si mesmo e seu grupo étnico/racial” (GOMES, p. 149). Essa negação é resultante do processo de escravidão, no qual o negro perde o status humano e é visto como coisa. Nesse sentido,

a coisificação social se chocava com a pessoa do escravo (pessoa = subjetividade humana). Ferida, humilhada, comprimida, a pessoa do escravo não era anulada (exceto em casos patológicos). A contradição entre ser coisa e ser pessoa constituía a vivência do escravo durante toda a sua existência (GOMES, 2006, p. $153)$.

Como outra estratégia de coisificação e de dominação, o escravo e a escrava tinham, em muitos casos, o cabelo raspado, como forma de mutilação e de dominação imposta pelo dono. Esse fato era também uma mutilação cultural, pois muitas etnias africanas consideravam o cabelo uma marca de identidade e de dignidade (GOMES, 2006, p. 27). Esse processo, teoricamente, teve fim com a abolição da escravatura, no entanto, o negro brasileiro continua vivendo uma tensão entre ser coisa e ser pessoa, agora com matizes diferentes, uma vez que a sociedade se diz uma democracia racial. Assim, “a contradição rejeitar-se e aceitar-se como negro e, mais ainda, rejeitar-se como negro para ser aceito socialmente, constitui a vivência cotidiana" dos sujeitos negros (GOMES, 2006, p. 154). Ademais, Gomes (2006, p. 162) ressalta que o negro se constrói como sujeito em uma "tensão entre uma imagem socialmente construída em um processo de dominação e a luta pela construção de uma auto-imagem positiva. Não permitir que tal imagem social destrua a auto-imagem positiva é um desafio".

Hoje, mudar o cabelo pode ser uma forma de sair do lugar de inferioridade (GOMES, 2006, p. 21). Assim, para homens e mulheres negras, a manipulação do corpo e do cabelo pode ter o sentido de aproximação do estereótipo branco e de afastamento do negro (GOMES, 2006, p. 142). Tal comportamento é decorrente do fato de a sociedade hierarquizar grupos étnicos e estéticos, minimizando e desprezando negros por considerá-los fora do padrão ideal.

A conjunção desses fatores mostra que as ideologias da supremacia branca atacam a inteligência, a beleza, a capacidade e o caráter do negro, que precisa reagir a essa construção discursivo-social (WEST, 2002, p.10). Assim, as práticas de supremacia branca, sustentadas por 
autoridades culturais, pela mídia e pelos meios científicos, promovem a inferiorização do negro e constituem-se como pano de fundo que leva às lutas por sua identidade (respeito, confiança e estima) e por recursos econômicos.

De outro ponto de vista, Roger Bastide, em estudo da representação do negro na literatura brasileira, lista elementos associados à raça negra que auxiliam na construção de identidades subalternas: o negro (de modo genérico) é feio, ruim, cruel, grotesco, risível, feiticeiro, mágico, supersticioso; é um animal sensual e sexual; tem caráter infantil ou excessivamente inocente (que o liga ao primitivismo); relaciona-se à sujeira e à embriaguez; a negra (a mulher especificamente) é cheia de manhas, tagarela, preguiçosa; ama o prazer e o luxo. Essas representações são encontradas em obras de vários autores, principalmente nos ligados ao Romantismo. Da pesquisa empreendida, Bastide apresenta alguns estereótipos (apud CASTRO, 2007, p. 23):

- o negro bom (estereótipo da submissão);

- o negro ruim (estereótipo da crueldade nativa e da sexualidade sem freios);

- o africano (estereótipo da feiúra, da brutalidade, da feitiçaria ou da superstição);

- o crioulo (estereótipo da astúcia, da habilidade e do servilismo enganador);

- mulato livre (estereótipo da vaidade pretensiosa e ridícula); e

- a crioula ou mulata (estereótipo da volúpia).

Gomes (2006), ao pesquisar cabelo e corpo como símbolos da identidade negra, concluiu que eles se destacam como veículo de expressão e de resistência social e cultural e como formas de opressão e de negação. Assim, o cabelo crespo pode ser visto como sinal diacrítico que imprime a negritude no corpo ou como rejeição da própria imagem.

Essas oposições entre cabelos crespos e lisos são acentuadas pela mídia, que reforça a existência de apenas duas possibilidades extremas entre as milhares de configurações que os cabelos podem assumir em um país miscigenado como o nosso. Quando esses tipos de cabelo são comparados, o crespo é associado a desleixo, a desarrumação, a descontrole. Assim, o cabelo negro usado de modo natural (crespo) precisa ser domado para atender às expectativas sociais.

Exemplos significativos são apresentados nas ilustrações abaixo, que compõem uma campanha da Seda destinada a vender produtos para cabelos crespos. As principais qualidades do produto são o controle do volume e a ação antifrizz ${ }^{9}$, que prometem domar fios rebeldes e

\footnotetext{
${ }^{9}$ Frizz do inglês significa encrespar ou frisar.
} 
eletrizados ${ }^{10}$. Logo, a vantagem dos produtos é neutralizar as principais características do cabelo negro e adequá-lo ao padrão branco.

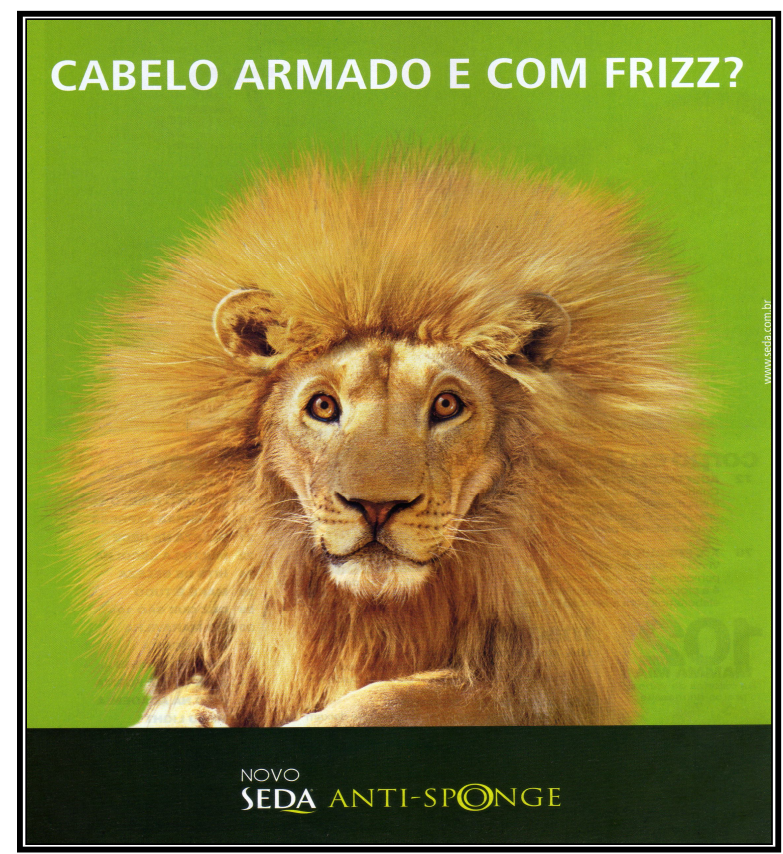

Fonte: Revista Corpo a corpo, ano XIX, n. 209, p. 10.

A forma indesejada deve ser domada, harmonizada por meio de tratamentos e de produtos para atingir o ideal socialmente almejado. Entretanto, "harmonia não é uniformidade; é sempre uma ação recíproca da vários motivos diferentes, cada um mantendo sua identidade separada e sustentando a melodia resultante dessa identidade" (BAUMAN, 2009, p. 123). Segundo Bauman, a harmonia somente será alcançada quando as identidades separadas não almejarem exclusividade, não se recusarem a coabitar com as outras e isso

requer abandonar a tendência de suprimir outras identidades em nome da autoafirmação de uma em particular e aceitar que proteger as outras identidades é o que mantém a diversidade na qual nossa própria unicidade pode florescer. (BAUMAN, 2009, p. 123)

Para atender ao ideal socialmente estabelecido, os cabelos devem ser tratados para chegar ao resultado apresentado abaixo.

\footnotetext{
${ }^{10}$ Dados retirados do site <www.unilever.com.br/ourcompany/newanmidia/pressreleases/2006/antifrizz〉, em 26 de junho de 2009.
} 


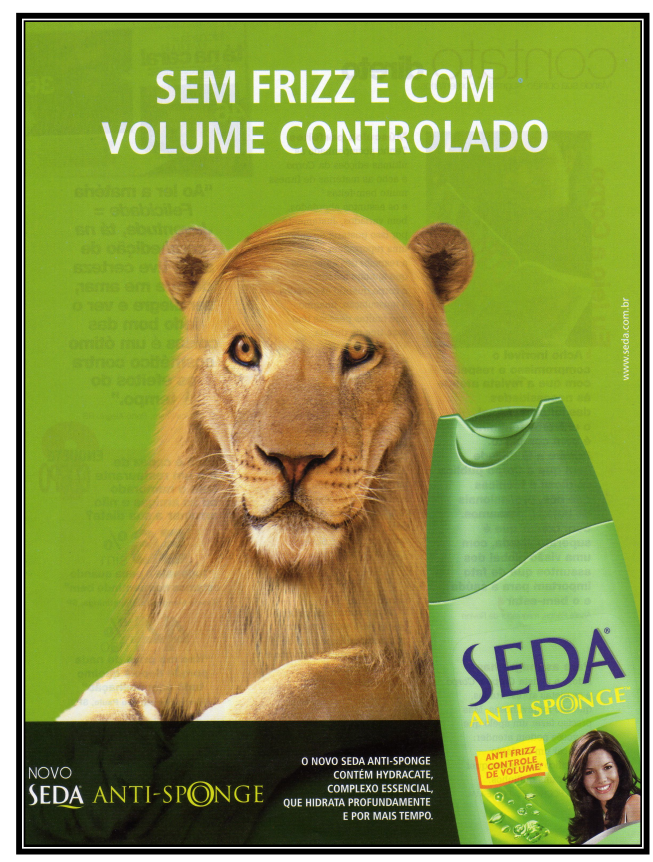

Fonte: Revista Corpo a corpo, ano XIX, n. 209, p. 10.

Essas transformações ocorrem nos salões de beleza, entendidos por Santos (2000) como locais que auxiliam o negro(a) a criar uma estética "alternativa", elaborando e reelaborando uma autoimagem, o que vai de encontro ao modelo de representação dominante nas sociedades ocidentais. Nesses locais, o ideal de beleza é uma unidade por ser oposto ao ocidental, mas é fragmentado por apresentar traços e detalhes que retomam o modelo branco de estética do mercado.

Como parte importante para a composição da beleza, os cabelos crespos são submetidos a tratamentos como ferro quente, pastas alisantes, dread locks, tranças rastafari e outros processos para atingir o aspecto ideal: lisos e compridos e para refletir o ideal branco de beleza. Para Santos (2000, p. 56), isso acontece porque "deixar o cabelo crescer naturalmente significa reconhecer a origem africana", uma vez que o cabelo negro é diferente do modelo eleito pela mídia. Logo, ter cabelos que são aparentemente mais secos, que têm pouco brilho, que não são maleáveis remete à ideia de pouco cuidado com a aparência.

Entretanto, o salão pode ser um local de afirmação da beleza negra, de suas características e escolhas; podem ser pontos de reflexão para a criação ou a disseminação da "consciência negra" e da afirmação da identidade negra ou podem "mais que fazer o cabelo, fazer a cabeça" (SANTOS, 2000, p. 58). Com relação ao modelo de beleza negra, Santos (2000, p. 51) esclarece que a "beleza negra" teve sua formação nos anos de 1970 e se solidificou na década de 1980. Nessa época, um dos fatores mais relevantes foi a criação de bonecas negras. Essa produção é significativa para a formação da identidade de crianças negras, visto que, nas 
brincadeiras, elas podem se identificar com um modelo e se verem representadas de forma natural, descartando as bonecas tipo Barbie, que reforçam o padrão de beleza branco. De outro lado, somente no mesmo período (1970-1980), apareceu a preocupação das indústrias em produzir maquiagens e produtos de beleza para a estética da mulher negra.

\section{Crises identitárias étnico-raciais: o bônus e o ônus}

Uma vez analisados esses aspectos constitutivos da crise de identidades étnico-raciais no Brasil, é necessário sistematizar algumas ideias. Primeira: identidades e crises são indissociáveis. Logo, passar por essas crises não é particularidade de negros, nem da construção das identidades étnico-raciais. Todas as identidades que assumimos ou negamos são resultantes de crise(s) (que não necessariamente acabam). Segunda: a crise não necessariamente é ruim. Ela é parte do processo de constituição, de aceitação, de negociação e de negação das identidades; e é necessária para que valores, discursos e práticas, associados a cada uma delas, sejam avaliados, aceitos, negociados ou negados. Nesse sentido, a crise pode ser vista positivamente, uma vez que oferece a possibilidade de se transitar entre as possíveis identidades que o sujeito tem à sua disposição.

Para concluir esse levantamento teórico, é preciso considerar que, no mundo moderno, as culturas nacionais constituem uma das principais fontes de identidade cultural. Porém, longe de ser algo espontâneo e natural, toda identidade é construída e fabricada em processos linguísticos e sociais de natureza ideológica. É inegável que o local onde nascemos condiciona nossa nacionalidade ou naturalidade. No entanto, não podemos deixar de constatar que a identificação de um sujeito com determinada região geográfica, antes de ser um dado que lhe é natural, é, de fato, fruto de um processo de construção social e discursiva. Há estratégias representacionais acionadas para construir um senso comum acerca do pertencimento a um grupo.

Identidade, portanto, é uma questão discursiva. Diferentemente do que o senso comum costuma acreditar, a identidade social não é algo dado, algo peculiar a um indivíduo ou grupo porque ele é naturalmente como é (nordestino, gay, negro, judeu); ao contrário, as identidades são realizadas como trabalho simbólico dos indivíduos em sua cultura e com sua cultura. Não existe uma relação direta entre atribuições de identidade e mundo "real". Entre um e outro, existe uma mediação, constituída pelos processos de apreensão e de elaboração simbólica, que inclui, em especial, estratégias de mediação linguístico-discursivas. A forma como falamos de nós mesmos, dos outros e com os outros representa uma prática identitária com um ethos próprio (MAGALHÃES, 2001). 
Finalmente, no que tange à questão dos padrões de beleza, eles também não são uma particularidade de nosso contexto social, posto que todas as sociedades os produzem, naturalizam e legitimam por vários meios, sendo a mídia apenas um deles.

Entretanto, é necessário pensar nos valores que atribuímos a esses padrões e no quão prejudiciais podem se tornar em função da valoração excessiva. Além disso, não podemos acatar passivamente uma equação cruel resultante desses padrões na qual se assentam muitas ideias preconceituosas e racistas, pois, para muitos, a noção de beleza associa-se a outras e cria a seguinte equação:

$$
\begin{gathered}
\text { Branco }=\text { belo }=\text { bom } \\
\text { Negro }=\text { feio }=\text { ruim }
\end{gathered}
$$

Portanto, mais que questionar a construção das identidades, é preciso também refletir sobre suas consequências.

\section{Referências}

BAUMAN, Z. A sociedade individualizada. Vidas contadas e histórias vividas. Rio de Janeiro: Jorge Zahar, 2009.

Identidade. Rio de Janeiro: Jorge Zahar, 2005.

Modernidade Líquida. Rio de Janeiro: Jorge Zahar, 2001.

CASTRO, S. R. L. de. Corpo e erotismo em Cadernos Negros: a reconstrução semiótica da liberdade. Dissertação de Mestrado, Universidade de São Paulo, 2007.

CHAVEZ, E. R. Notas sobre la identidad cubana e su relación con la diáspora. Revista Temas, Cuba, n. 28, Nueva Época, jan./mar. , 2002

CORACINI, M. J.(Org.). Identidade e discurso: (des)construindo subjetividades. Campinas: Editora Unicamp, 2003.

DE LA TORRE, C. Identidad e identidades. Revista Temas, Cultura, Ideología, Sociedad, Cuba, n. 28, Nueva Época, jan./mar. 2002.

DUBAR, C. A crise das identidades. A interpretação de uma mutação. Porto: Afrontamentos, 2006.

FANON, F. Pele negra, máscaras brancas. Porto: Orgal, 1980

GOMES, N. L. Sem perder a raiz. Corpo e cabelo negro como símbolos da identidade negra. Belo Horizonte: Autêntica, 2006.

HALL, S. Da diáspora. Identidades e mediações culturais. Belo Horizonte: EFMG, 2006.

LE BRETON, D. Sinais da identidade. Tatuagens, piercings e outras marcas corporais. Lisboa: Miosótis, 2004.

MAGAlHÃES, C. A Análise Crítica do Discurso enquanto Teoria e Método de Estudo. In: MAGALHÃES, C. (Org.). Reflexões sobre a Análise Crítica do Discurso. Belo Horizonte: FALE/UFMG, 2001.

MARTINS, J. S. O branco da consciência negra. In: FRY, Peter et al. (Org.). Divisões perigosas. Políticas raciais no Brasil contemporâneo. Rio de Janeiro: Civilização Brasileira, 2007.

NOVAES, J. de V. O intolerável peso da feiura. Rio de Janeiro: Editora PUC/Garamond, 2006.

OLIVEIRA, R. C. Caminhos da Identidade. São Paulo: Editora Unesp/Brasília: Paralelo 15, 2006.

OLIVEIRA, E. Mulher negra. Professora universitária. Trajetória, Conflitos e Identidade. Brasília: Líber Livro, 2006.

PIERUCCI, A. F. Ciladas da diferença. São Paulo: Editora 34, 1999.

SANTOS, J. T. O negro no espelho: imagens e discursos nos salões de beleza étnicos. Estudos Afro-Asiáticos 38, Rio de Janeiro, Universidade Cândido Mendes, 2000.

SILVA, T. T. Identidade e diferença. A perspectiva dos Estudos Culturais. Rio de Janeiro: Vozes, 2000.

WEST, C. Las nuevas politicas culturales de la diferencia. Revista Temas, Cultura, Ideología, Sociedad, Cuba, n. 28, Nueva Época, jan./mar. 2002.

WODAK, R. Círculos específicos e discurso anti-semita: a construção do discurso do “outro”. In: PEDRO, Emília R. (Org.). Análise Crítica do Discurso. Lisboa: Caminho, 1998.

WOODWARD, K. Identidade e diferença: uma introdução teórica e conceitual. In: SILVA, Tomaz Tadeu da. Identidade e diferença. A perspectiva dos Estudos Culturais. Rio de Janeiro: Vozes, 2000. 